\title{
Impacts of future climate change on agroclimatic resources in Northeast China
}

\author{
CHU Zheng ${ }^{1}$, "GUO Jianping ${ }^{1,2}$, ZHAO Junfang ${ }^{2}$ \\ 1. Nanjing University of Information Science and Technology, Nanjing 210044, China; \\ 2. Chinese Academy of Meteorological Sciences, Beijing 100081, China
}

\begin{abstract}
In this study, the spatial distribution and changing trends of agricultural heat and precipitation resources in Northeast China were analyzed to explore the impacts of future climate changes on agroclimatic resources in the region. This research is based on the output meteorological data from the regional climate model system for Northeast China from 2005 to 2099, under low and high radiative forcing scenarios RCP4.5 (low emission scenario) and RCP8.5 (high emission scenario) as proposed in IPCC AR5. Model outputs under the baseline scenario, and RCP4.5 and RCP8.5 scenarios were assimilated with observed data from 91 meteorological stations in Northeast China from 1961 to 2010 to perform the analyses. The results indicate that: (1) The spatial distribution of temperature decreases from south to north, and the temperature is projected to increase in all regions, especially under a high emission scenario. The average annual temperature under the baseline scenario is $7.70^{\circ} \mathrm{C}$, and the average annual temperatures under RCP4.5 and RCP8.5 are $9.67^{\circ} \mathrm{C}$ and $10.66^{\circ} \mathrm{C}$, respectively. Other agricultural heat resources change in accordance with temperature changes. Specifically, the first day with temperatures $\geq 10^{\circ} \mathrm{C}$ arrives 3 to $4 \mathrm{~d}$ earlier, the first frost date is delayed by 2 to $6 \mathrm{~d}$, and the duration of the growing season is lengthened by 4 to $10 \mathrm{~d}$, and the accumulated temperature increases by 400 to $700^{\circ} \mathrm{C} \cdot \mathrm{d}$. Water resources exhibit slight but not significant increases. (2) While the historical temperature increase rate is $0.35^{\circ} \mathrm{C} / 10 \mathrm{a}$, the rate of future temperature increase is the highest under the RCP8.5 scenario at $0.48^{\circ} \mathrm{C} / 10 \mathrm{a}$, compared to $0.19^{\circ} \mathrm{C} / 10 \mathrm{a}$ under the RCP4.5 scenario. In the later part of this century, the trend of temperature increase is significantly faster under the RCP8.5 scenario than under the RCP4.5 scenario, with faster increases in the northern region. Other agricultural heat resources exhibit similar trends as temperature, but with different specific spatial distributions. Precipitation in the growing season generally shows an increasing but insignificant trend in the future, with relatively large yearly fluctuations. Precipitation in the eastern region is projected to increase, while a decrease is expected in the western region. The future climate in Northeast China will change towards higher temperature and humidity. The heat resource will increase globally, however its disparity with the change in precipitation may negatively affect agricultural activities.
\end{abstract}

Keywords: climate change; agroclimatic resources; Northeast China

Received: 2016-08-08 Accepted: 2017-02-22

Foundation: National Natural Science Foundation of China, No.31371530; Jiangsu Province Innovative Postgraduate Training Program, No.KYLX_0846

Author: Chu Zheng (1985-), PhD, specialized in agricultural meteorology and related fields. E-mail: chuzheng1985@126.com

*Corresponding author: Guo Jianping (1963-), PhD and Professor, E-mail: gjp@camscma.cn 


\section{Introduction}

In recent years, the issue of climate change as represented by rising temperatures is receiving intense research interest. Its influence encompasses many aspects of human activities, such as environment, agriculture, manufacturing and industry, and livelihood (ALexandrov and Hoogenboom, 2000; Tang et al., 2000; Füssel and Klein, 2006). Research indicates that by 2100 , it is possible that the global temperature could increase by more than $2{ }^{\circ} \mathrm{C}$ (Solomon, 2007). Agriculture is arguably the most sensitive sector to climate change, and will thus be impacted greatly by climate change. Changes in agroclimatic resources such as light, heat and water will directly alter the agricultural production condition and level (Li et al., 2010a), and ultimately determine the quantity and quality of agricultural production (Yu et al., 1985; Li et al., 2003). Research shows that in the past 50 years, China's climate has become warmer and drier as a whole. In terms of regions, Southwest, North and Northeast China are trending warmer and drier, while Northwest and South China are trending warmer and wetter (Liu et al., 2009; Li et al., 2010b; Dai et al., 2011; Yang et al., 2011). Due to the impact of the temperature increase, wheat production in China could be reduced by $15 \%$ and corn production may also decrease (Yang et al., 2014; Ma et al., 2015). The change in precipitation increases the frequency of drought and flood events, which changes soil humidity and runoff, and reduces the available water resource for crops. Therefore, changes in agroclimatic resources are of crucial importance to food security.

Based on the intensity of atmospheric radiation $\left(2.6-8.5 \mathrm{~W} / \mathrm{m}^{2}\right)$, the Intergovernmental Panel on Climate Change (IPCC) Fifth Assessment Report (AR5) proposed four representative concentration pathway (RCP) scenarios, and it incorporated policy factors for the first time. The four RCPs are: RCP2.6, RCP4.5, RCP6 and RCP8.5. Compared to the 2007 Special Report on Emissions Scenarios (SRES) in AR4, RCPs based models show better performance in simulating extreme weather events (Hu and Liu, 2013). When applied to evaluating agriculture, which is more sensitive to daily climate change, RCP results are more realistic. The northeastern region, i.e., Northeast China (Heilongjiang, Jilin and Liaoning provinces, and the four leagues of eastern Inner Mongolia) is regarded as a climate change sensitive area. Its average temperature has increased by $1.70^{\circ} \mathrm{C}$ in the past 50 years, significantly higher than the global average warming of $0.74^{\circ} \mathrm{C} / 100 \mathrm{a}(\mathrm{Li}, 2012)$. Meanwhile, Northeast China accounts for $22.9 \%$ of all arable land of the country, and the food grain yield is approximately one-third of the total domestic food yield, with $80 \%$ of planting areas used for growing major food crops including rice (Oryza sativa), maize and soybeans (Wu et $a l ., 2014)$. The region plays an important role in China's food security. As such, what impact will future climate change have on agroclimatic resources in Northeast China? It will have a direct impact on agricultural layout and grain yield, and influence Chinese food production safety strategy. However, as of 2015, only a few scholars have analyzed the changes of growing seasons in Liaoning and Ningxia over the next 50 years by using SRES scenarios from AR4. Presently, there are no related researches on changes to the northeastern climate resources under multiple future climate change scenarios. This study utilizes the latest RCPs future scenarios data from the 5th IPCC report and incorporates historical resources (baseline) to perform an accurate analysis of the spatiotemporal evolution of agroclimatic resources under the influence of climate change in Northeast China. The objective of this research is to provide a more rational scientific basis for developing and utilizing agroclimatic 
resources, and for guiding agricultural production responses to possible future climate change.

\section{Data resources and processing}

This study used atmospheric radiation strength $\left(2.6-8.5 \mathrm{~W} / \mathrm{m}^{2}\right)$ proposed by the National Climate Center based on the IPCC's Fifth Assessment Report (AR5), which includes three types of emission concentration drives (RCPrf, RCP4.5, RCP8.5). We adopted the regional climate model in BCC_CSM1.0 and daily meteorological elements data with a simulated spatial resolution of $0.5^{\circ} \times 0.5^{\circ}$. Among these three scenarios, RCPrf is the contemporary scenario data with simulated time series from 1951-2005, and is used primarily for data assimilation; RCP4.5 is the scenario that balances greenhouse gas emissions and economic development, with the highest priority on development; RCP8.5 is the highest pathway for greenhouse gas emissions. Both RCP4.5 and RCP8.5 have a simulated time series of 2006-2099.

The daily meteorological data was obtained from the national weather service meteorological data-sharing websites of the National Climate Center. It includes the daily average $(T)$, daily maximum $\left(T_{\max }\right)$, daily minimum $\left(T_{\min }\right)$ temperature, and daily precipitation data. Data are recorded at 91 weather stations in Northeast China from 1961 to 2010 (baseline). These historical data were primarily used to verify the simulation results.

Assimilation and verification process of simulated data:

To eliminate systematic errors in the simulation results on climate modes, we first assimilated the simulated data with recorded historical data from the same time period to obtain new data series with reduced systematic errors. The process can be described in detail as follows:

Assimilation method for climate elements that changed continuously:

$$
\begin{aligned}
X_{i}= & {\left[\bar{X}\left(\begin{array}{c}
\text { average of observed data } \\
\text { of the same day }
\end{array}\right)-\bar{X}_{1}\left(\begin{array}{c}
\text { average of simiuation data } \\
\text { of the same day }
\end{array}\right)\right] } \\
& +X_{i}\left(\begin{array}{c}
\text { simulation data } \\
\text { of a particular day }
\end{array}\right)
\end{aligned}
$$

Assimilation method for climate elements that did not change continuously:

$X_{i}=X_{i}$ (simulation data of a particular day) $\times \ldots, X$., average of observed data of a

-10 |day period where the day belongs..,$- X_{i}$, average of simulation data of a

-10 |day period where the day belongs|

The daily average temperature $(T)$, daily minimum temperature $\left(T_{\min }\right)$, daily maximum temperature $\left(T_{\max }\right)$ and annual precipitation $(P)$ after assimilation were verified individually (Table 1 and Figure 1). As shown, data series after assimilation showed increased accuracy and reduced error for each element compared to the data series before assimilation. Precipitation $(P)$ had the most significant reduction in absolute error, with the accuracy increased by $99 \%$. Accuracy improvement for $T_{\min }$ and $T_{\max }$ were $68 \%$ and $92 \%$, respectively. The accuracy for $T$ increased by $36 \%$. After assimilation, the root mean square error (RMSE) for all climate elements decreased (Figure 2). The reduction of RMSE for $P, T, T_{\max }$ and $T_{\min }$ was $50.01 \%, 34.58 \%, 13.94 \%$ and $18.10 \%$, respectively. Evidently, by assimilating and correcting the climate model simulation output data with recorded historical data, the climate 
modeling results became closer to the observed data. Therefore, this study used equations (1) and (2) to regenerate new data series for all elements with the 2006-2099 time scale.

Table 1 Assimilation results of the RCP data

\begin{tabular}{|c|c|c|c|c|c|c|c|}
\hline & \multirow{2}{*}{$\begin{array}{c}\text { Observed } \\
\text { data }\end{array}$} & \multicolumn{3}{|c|}{ Pre-assimilation } & \multicolumn{3}{|c|}{ Post-assimilation } \\
\hline & & Average value & Error & RMSE & Average value & Error & RMSE \\
\hline$P$ & 547.50 & 959.95 & 412.45 & 1.1238 & 540.20 & 7.30 & 0.5616 \\
\hline$T$ & 4.52 & 4.24 & 0.28 & 4.0893 & 4.70 & 0.18 & 2.9605 \\
\hline$T_{\min }$ & -1.18 & -0.43 & 0.75 & 3.6150 & -0.94 & 0.24 & 3.4786 \\
\hline$T_{\max }$ & 10.86 & 9.71 & 1.15 & 9.6059 & 11.07 & 0.21 & 8.2661 \\
\hline
\end{tabular}
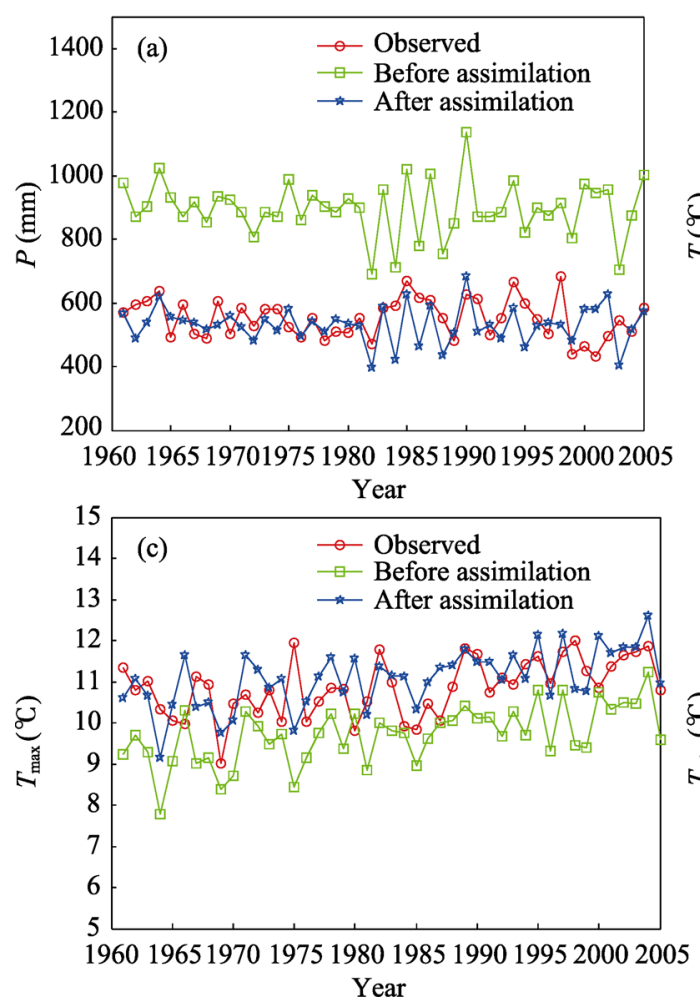
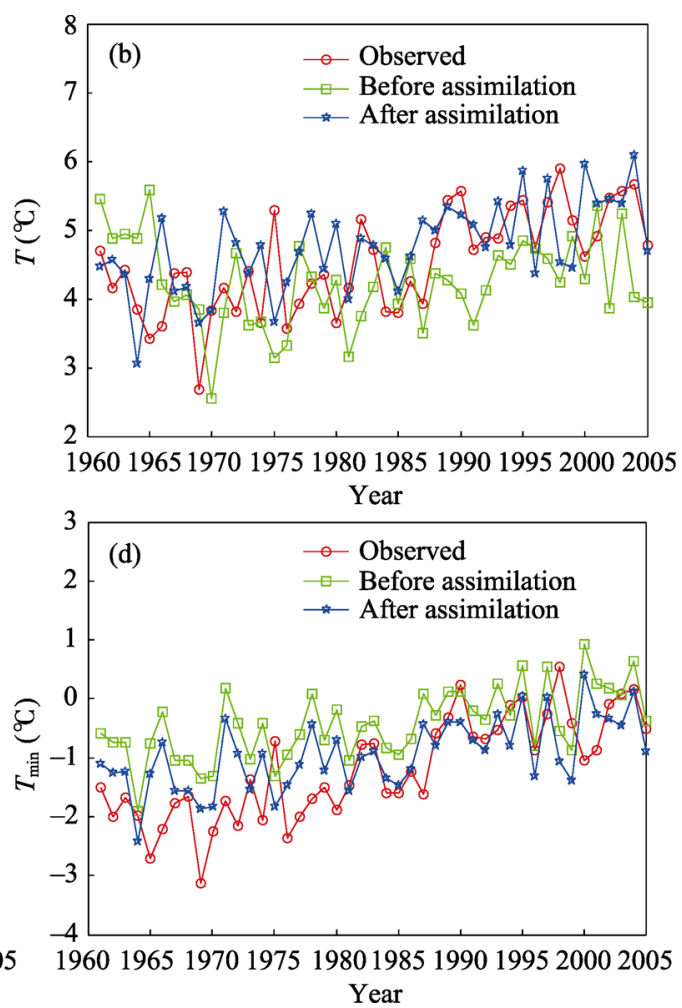

Figure 1 Comparison of different element data before and after assimilation with the observed data

\section{Methods}

\subsection{Agricultural temperature limits}

In Northeast China, generally the first day with temperatures $\geqslant 10^{\circ} \mathrm{C}$ marks the beginning of crop growth and the first frost day marks the end of crop growth. This time period is referred to as the potential growing season. The process to determine the occurrence dates of temperature limits is as follows: take the 5-day moving average (Liu et al., 2013), when the moving average is consistently above $10^{\circ} \mathrm{C}$, select the first five consecutive days that have moving average temperatures above $10^{\circ} \mathrm{C}$, and then select the first day with temperatures 
$\geqslant 10^{\circ} \mathrm{C}$ within the 5 days as the initial day. The first frost day is the first day in autumn when the daily minimum temperature is $\leqslant 2^{\circ} \mathrm{C}$. It is noted that crops can grow and reproduce between the first day with temperatures $\geqslant 10^{\circ} \mathrm{C}$ and the first frost day, this time period is therefore called the potential growing season.
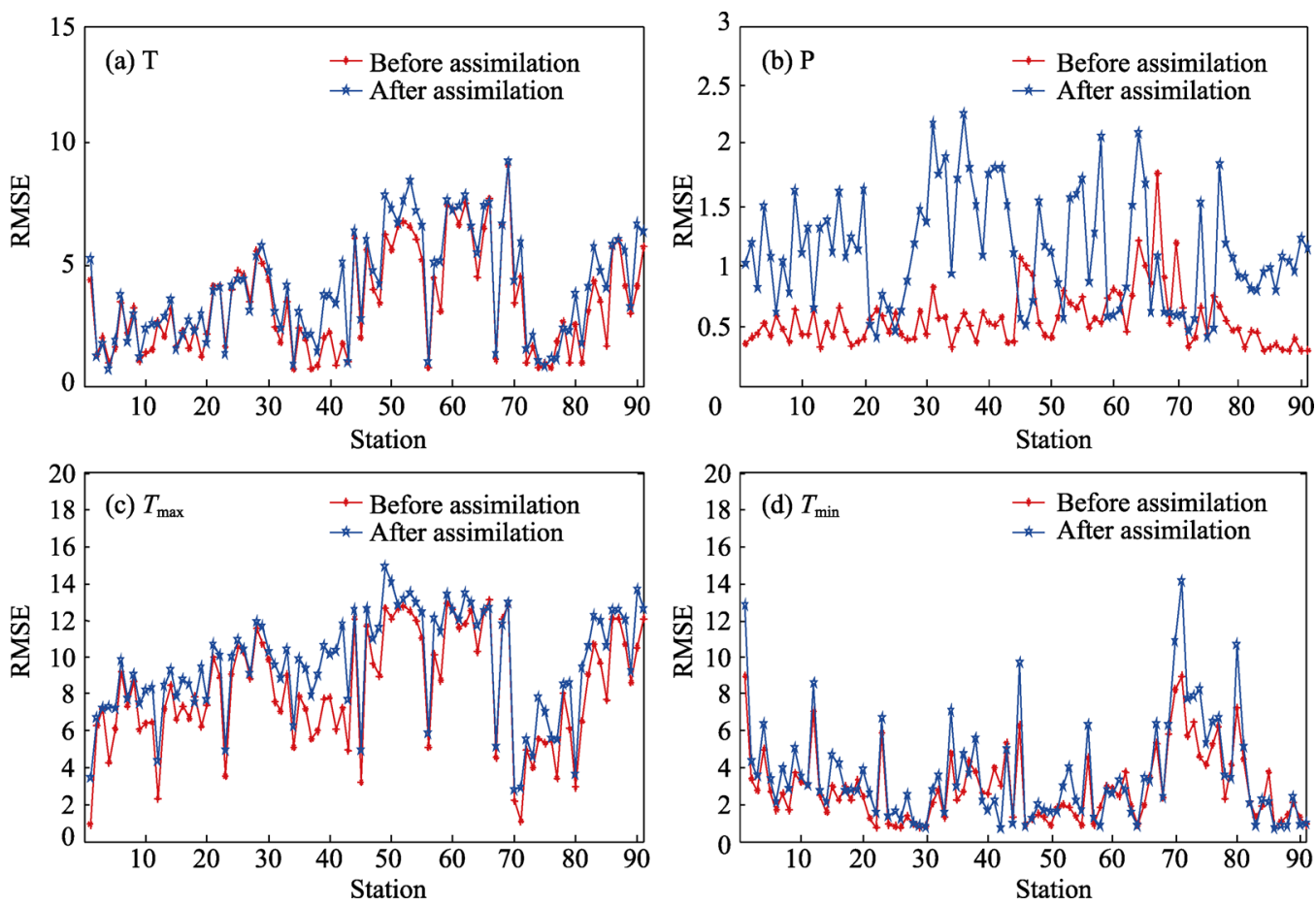

Figure 2 RMSE of the data before and after assimilation

\subsection{Assurance rate}

Precipitation assurance rate is the probability of precipitation above a certain threshold level. It is widely used in climate analysis for agriculture. The accumulated frequency of precipitation that is higher (or lower) than a certain threshold level is the precipitation assurance rate. For example, $80 \%$ precipitation assurance rate means the annual precipitation will be lower than this value only once every five years. It is calculated as follows:

$$
P_{m}=\frac{m}{n+1} \times 100 \%
$$

where $m$ is the serial number of all elements ranking from maximum to minimum, $n$ is the sample size and $P_{m}$ is the assurance rate of the serial number $m$.

\section{Results and discussion}

\subsection{Future change in heat resources in Northeast China}

Heat resources cover five factors in our study, namely, annual average temperature, first day with temperatures $\geqslant 10^{\circ} \mathrm{C}$, first frost day, potential growing season, and $\geqslant 10^{\circ} \mathrm{C}$ accumulated temperature. 


\subsubsection{Change in annual average temperature}

Compared to the baseline scenario, RCP4.5 and RCP8.5 showed increasing annual average temperatures (Table 2, Figures 3 and 4). Spatially, under RCP4.5, RCP8.5 and baseline scenarios, identical accumulated temperature zones were all moving north, with their areas expanding. Under the RCP4.5 scenario, zones below $0^{\circ} \mathrm{C}$ were significantly reduced in area, and zones over $12^{\circ} \mathrm{C}$ emerged in the south, which was absent in baseline. Under RCP8.5, zones below $0^{\circ} \mathrm{C}$ disappeared entirely, and zones over $12^{\circ} \mathrm{C}$ expanded to the north significantly.

Under both future RCP4.5 and RCP8.5 scenarios, temperature increased continuously and at a faster rate than baseline. The temperature continued to increase over the entire Songnen Plain area. However, under the baseline scenario, the slope of the annual temperature increase for the entire region was $0.35^{\circ} \mathrm{C} / 10 \mathrm{a}$. Compared to the baseline, the temperature increase rate is lower over the entire region at $0.19^{\circ} \mathrm{C} / 10 \mathrm{a}$ under the $\mathrm{RCP} 4.5$ scenario, while under the RCP8.5 scenario, the temperature increase rate is much faster (Table 3 ), with a slope of $0.48^{\circ} \mathrm{C} / 10 \mathrm{a}$.

Table 2 The $80 \%$ assurance rate of the annual average of agroclimatic resources from 1961 to 2099

\begin{tabular}{lcccccc}
\hline & $\begin{array}{c}\text { Annual average } \\
\text { temperature }\left({ }^{\circ} \mathrm{C}\right)\end{array}$ & $\begin{array}{c}\text { First day with } \\
\text { temperatures } \\
\geqslant 10^{\circ} \mathrm{C}(\mathrm{d})\end{array}$ & $\begin{array}{c}\text { First } \\
\text { frost } \\
\text { day }(\mathrm{d})\end{array}$ & $\begin{array}{c}\text { Potential } \\
\text { growing sea- } \\
\text { son }(\mathrm{d})\end{array}$ & $\begin{array}{c}\text { Accumulated temperature } \\
\text { for the growing season } \\
\left({ }^{\circ} \mathrm{C} \cdot \mathrm{d}\right)\end{array}$ & $\begin{array}{c}\text { Precipitation during } \\
\text { the growing season } \\
(\mathrm{mm})\end{array}$ \\
\hline Baseline & 7.70 & 128 & 292 & 183 & 3435 & 608 \\
$\mathrm{RCP} 4.5$ & 9.67 & 125 & 294 & 187 & 3867 & 624 \\
$\mathrm{RCP} 8.5$ & 10.66 & 124 & 298 & 193 & 4127 & 619 \\
\hline
\end{tabular}
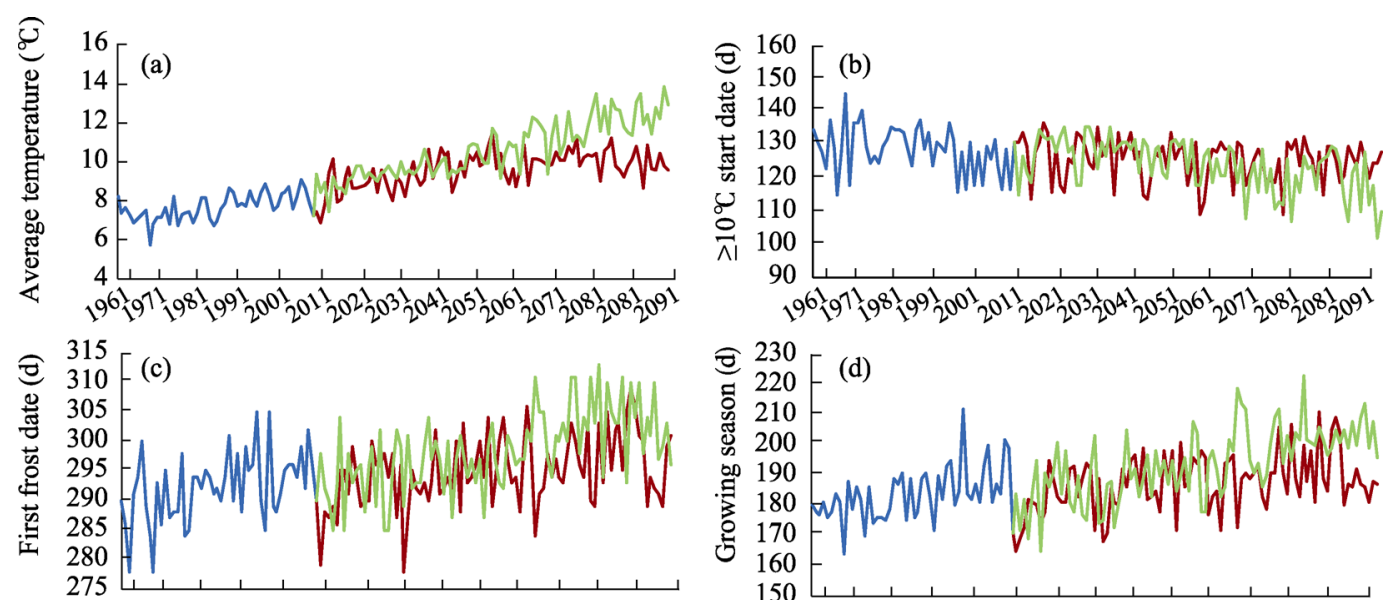

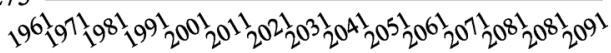
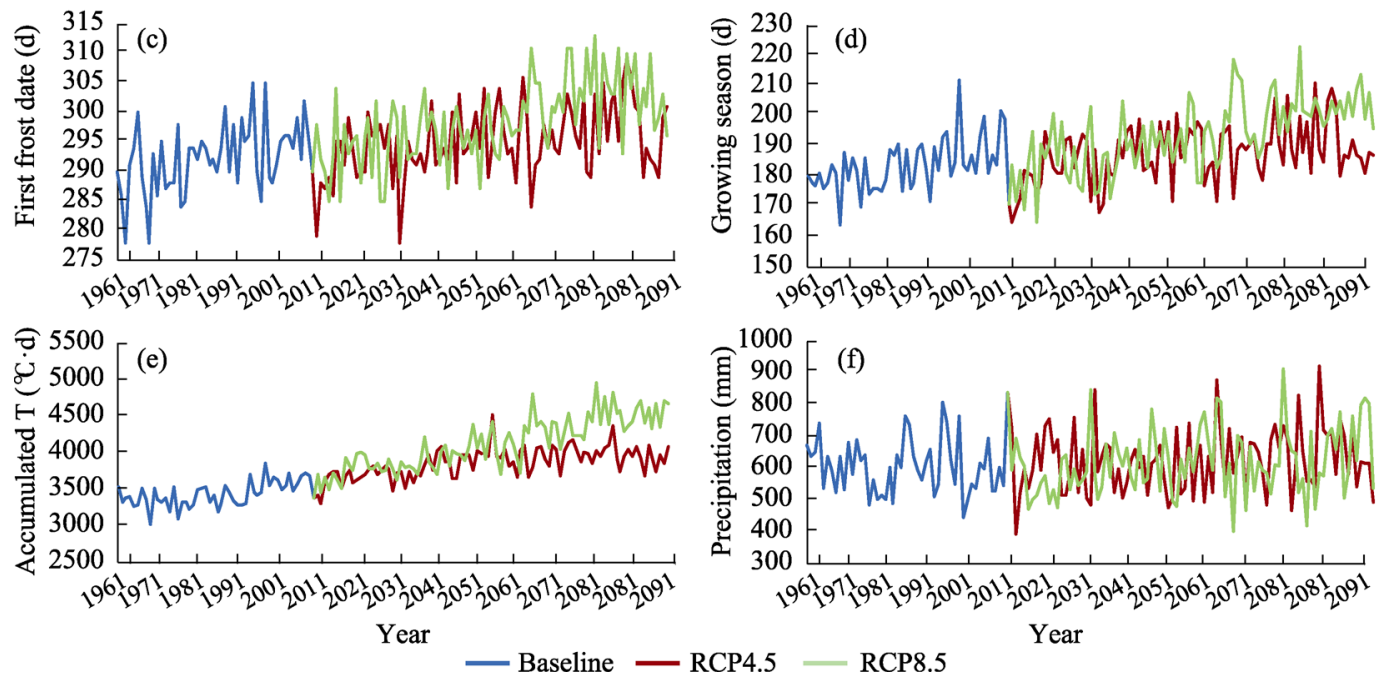

Figure 3 Change in 80\% assurance rate of agroclimatic resources in Northeast China from 1961 to 2099 
Table 3 Slope percentages of agroclimatic resources with 80\% assurance rate from 1961 to 2099 that are statistically significant $(\%)$

\begin{tabular}{|c|c|c|c|c|c|c|c|c|c|c|c|c|}
\hline & \multicolumn{2}{|c|}{ Temperature } & \multicolumn{2}{|c|}{$\begin{array}{l}\text { First day with } \\
\text { temperatures } \\
\quad \geqslant 10^{\circ} \mathrm{C}\end{array}$} & \multicolumn{2}{|c|}{ First frost day } & \multicolumn{2}{|c|}{$\begin{array}{l}\text { Potential grow- } \\
\text { ing season }\end{array}$} & \multicolumn{2}{|c|}{$\begin{array}{l}\text { Accumulated } \\
\text { temperature }\end{array}$} & \multicolumn{2}{|c|}{$\begin{array}{l}\text { Precipitation } \\
\text { during the grow- } \\
\text { ing season }\end{array}$} \\
\hline & $\begin{array}{l}\text { Signifi- } \\
\text { cant }\end{array}$ & $\begin{array}{c}\text { Highly } \\
\text { significant }\end{array}$ & $\begin{array}{l}\text { Signifi- } \\
\text { cant }\end{array}$ & $\begin{array}{l}\text { Highly } \\
\text { signifi- } \\
\text { cant }\end{array}$ & $\begin{array}{l}\text { Signifi- } \\
\text { cant }\end{array}$ & $\begin{array}{l}\text { Highly } \\
\text { signifi- } \\
\text { cant }\end{array}$ & $\begin{array}{l}\text { Signifi- } \\
\text { cant }\end{array}$ & $\begin{array}{l}\text { Highly } \\
\text { signifi- } \\
\text { cant }\end{array}$ & $\begin{array}{l}\text { Signifi- } \\
\text { cant }\end{array}$ & $\begin{array}{l}\text { Highly } \\
\text { signifi- } \\
\text { cant }\end{array}$ & $\begin{array}{l}\text { Signifi- } \\
\text { cant }\end{array}$ & $\begin{array}{l}\text { Highly } \\
\text { signifi- } \\
\text { cant }\end{array}$ \\
\hline Baseline & 99 & 98 & 3 & 4 & 43 & 28 & 48 & 26 & 87 & 83 & 0 & 0 \\
\hline $\mathrm{RCP} 4.5$ & 100 & 100 & 76 & 46 & 96 & 93 & 94 & 83 & 100 & 100 & 0 & 0 \\
\hline RCP8.5 & 100 & 100 & 100 & 100 & 100 & 100 & 100 & 100 & 100 & 100 & 0 & 0 \\
\hline
\end{tabular}

(a) Baseline

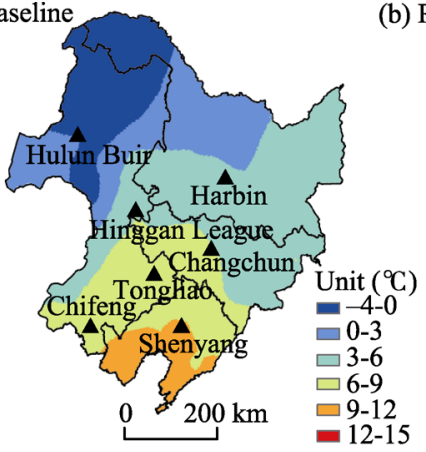

(b)

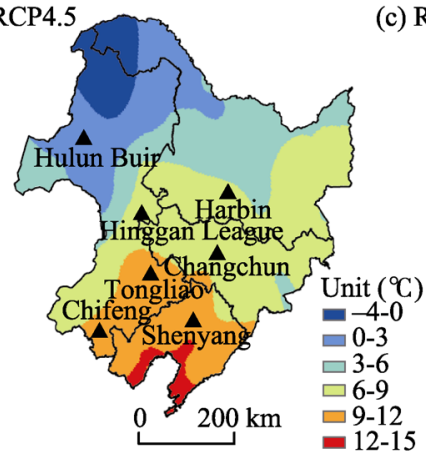

(c) RCP8.5

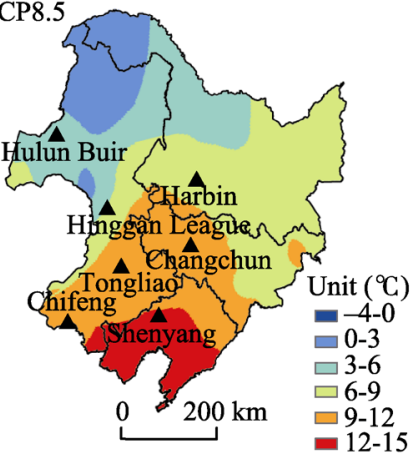

(d) Baseline

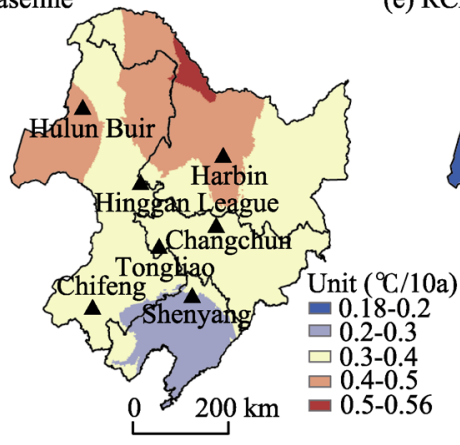

(e) RCP4.5

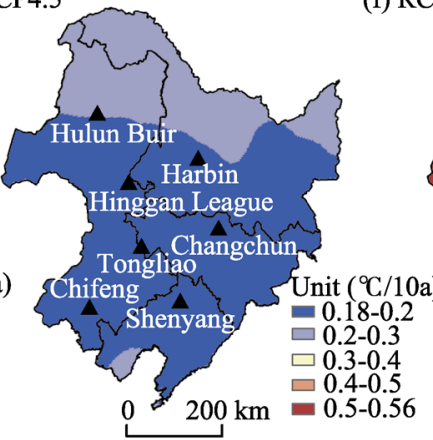

(f) RCP8.5

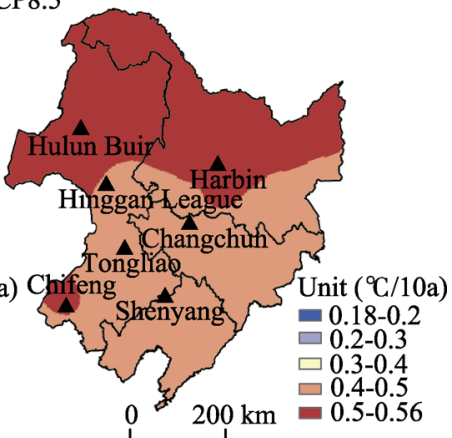

Figure 4 Distribution of annual average temperature (a, b, c) and climate slope (d, e, f) with $80 \%$ assurance rate in Northeast China

\subsubsection{Change in the first day with temperatures $\geqslant 10^{\circ} \mathrm{C}$ in Northeast China}

Compared to the baseline scenario, the first day with temperatures $\geqslant 10^{\circ} \mathrm{C}$ under $\mathrm{RCP} 4.5$ and RCP8.5 scenarios arrives $3 \mathrm{~d}$ and $4 \mathrm{~d}$ earlier, respectively. With $80 \%$ assurance rate, the first day with temperatures $\geqslant 10^{\circ} \mathrm{C}$ in Songnen Plain region arrived earlier, gradually from south to north (Figure 5). Under the baseline scenario, regions under $100 \mathrm{~d}$ concentrated in the south and center of Liaoning Province. Under RCP 4.5 and RCP 8.5 scenarios, these regions increased in area and expanded to the north significantly. Under RCP 8.5, regions under $100 \mathrm{~d}$ nearly covered the entire Liaoning Province, while the 100-110 d region covered most of Jilin Province and expanded north to the east of Heilongjiang Province. The region over $130 \mathrm{~d}$ accounted for an insignificant portion of Northeast China and mostly occupied areas north of Inner Mongolia. 
(a) Baseline

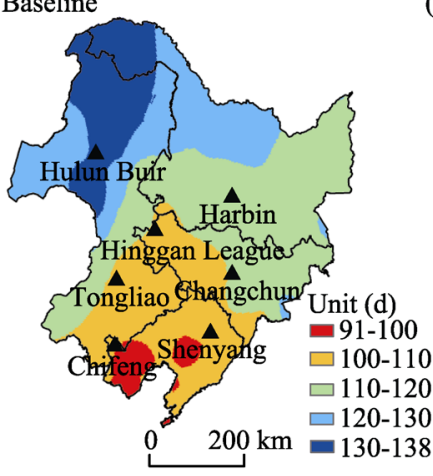

(b) RCP4.5

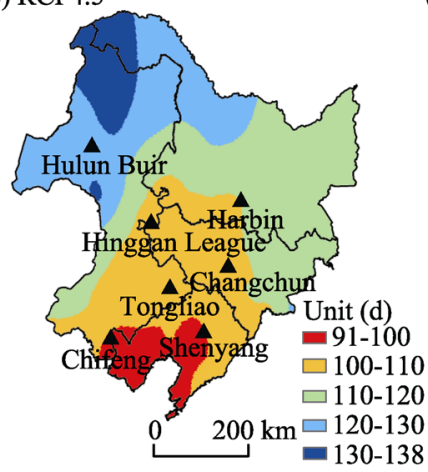

(c) RCP8.5

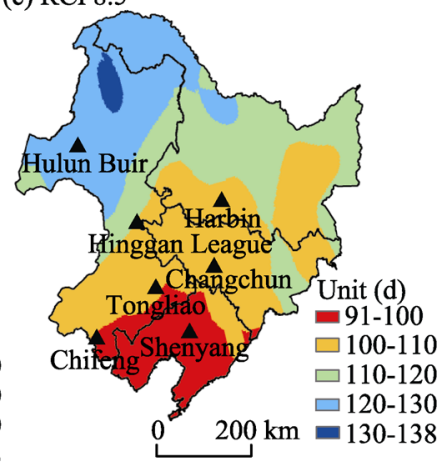

(d) Baseline

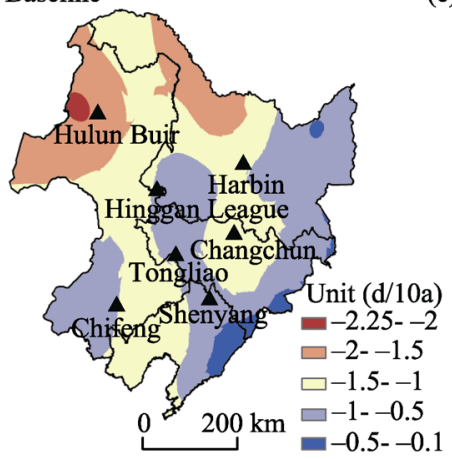

(e) RCP4.5

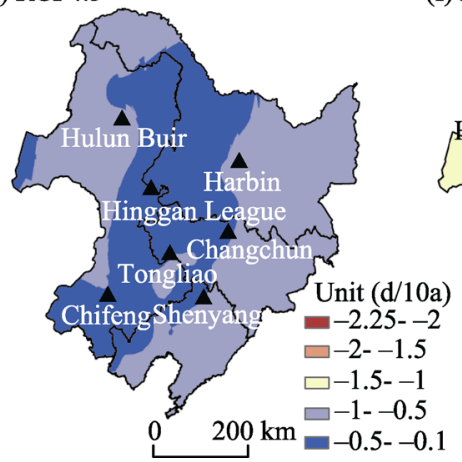

(f) RCP8.5

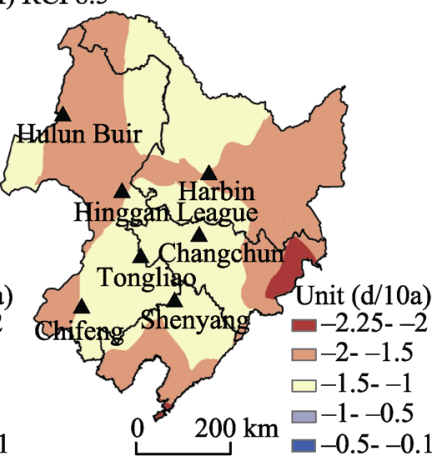

Figure 5 Spatial distribution of the first day with temperatures $\geqslant 10^{\circ} \mathrm{C}(\mathrm{a}, \mathrm{b}, \mathrm{c})$ and climate slope $(\mathrm{d}, \mathrm{e}, \mathrm{f})$ with $80 \%$ assurance rate

Under future RCP 4.5 and RCP 8.5 scenarios, the first day with temperatures $\geqslant 10^{\circ} \mathrm{C}$ showed a trend of gradually arriving earlier. The average slope under baseline is $-1.02 \mathrm{~d} / 10 \mathrm{a}$. The slopes for RCP 4.5 and RCP 8.5 scenarios are $-0.54 \mathrm{~d} / 10 \mathrm{a}$ and $-1.51 \mathrm{~d} / 10 \mathrm{a}$, respectively. Although the slope for RCP 4.5 was smaller than the baseline slope, the first day with temperatures $\geqslant 10^{\circ} \mathrm{C}$ was still trending earlier. This trend is observed throughout the entire Songnen Plain region. Compared to the baseline scenario, the early arrival trend for the first day with temperatures $\geqslant 10^{\circ} \mathrm{C}$ subsided over the whole region under the RCP4.5 scenario, while the arrival of the first day with temperatures $\geqslant 10^{\circ} \mathrm{C}$ advanced significantly faster over the entire region under RCP 8.5 (Table 3).

\subsubsection{Change in the first frost day in Northeast China}

Compared to the baseline scenario, under RCP4.5 and RCP8.5 scenarios, the first frost day was delayed by $2 \mathrm{~d}$ and $6 \mathrm{~d}$, respectively. With $80 \%$ assurance rate, the first frost day in Songnen Plain region was gradually delayed from north to south (Figure 6). The region over $330 \mathrm{~d}$ did not exhibit a significant change. The region over $300 \mathrm{~d}$ was concentrated in the south and center of Liaoning Province under the baseline scenario, expanding to the north under both RCP4.5 and RCP8.5 scenarios. Under the RCP8.5 scenario, the region over $300 \mathrm{~d}$ nearly occupied the entire Liaoning Province, and the 270-280 d region moved north almost out of Jilin Province and was reduced to the north of Heilongjiang Province. The under 280 $\mathrm{d}$ region only occupied areas north of the Greater Khingan Mountains and small areas in the north of Inner Mongolia in Northeast China. 

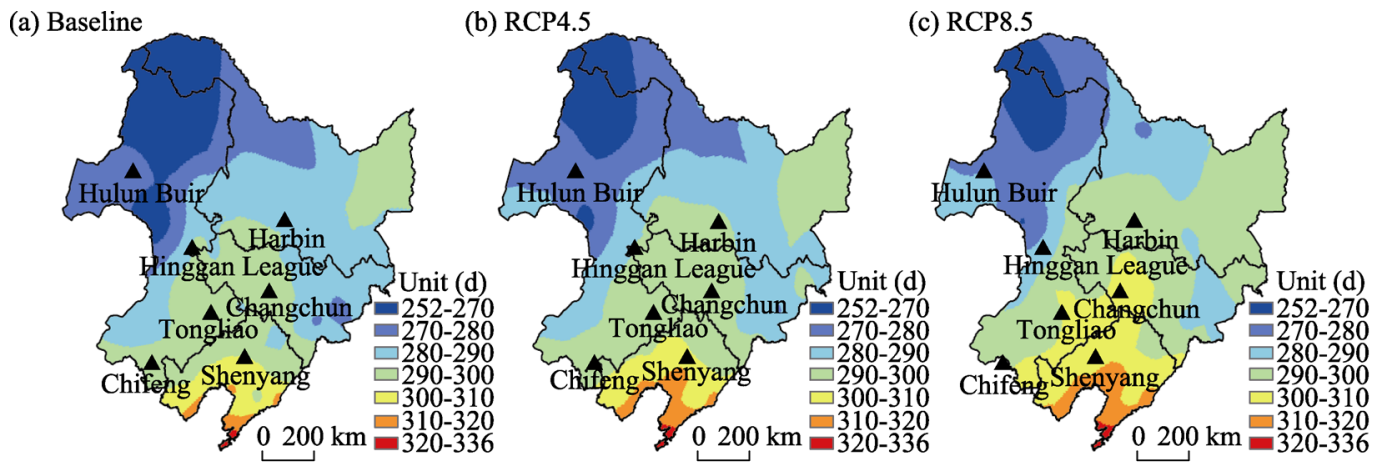

(d) Baseline

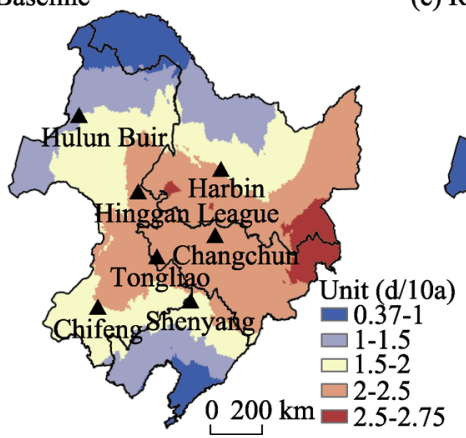

(e) RCP4.5

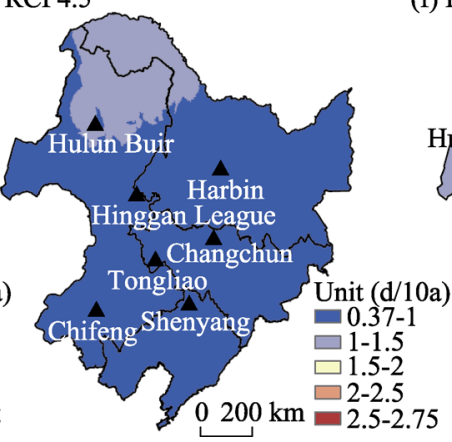

(f) RCP8.5

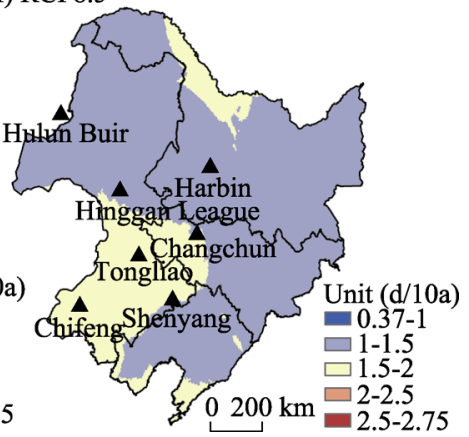

Figure 6 Spatial distribution of first frost day $(a, b, c)$ and climate slope (d, e, f) with $80 \%$ assurance rate in Northeast China

Under future RCP4.5 and RCP8.5 scenarios, the first frost day in Songnen Plain region was gradually delayed with a slope lower than the baseline $(1.78 \mathrm{~d} / 10 \mathrm{a})$. The slopes under RCP4.5 and RCP8.5 scenarios are $0.75 \mathrm{~d} / 10 \mathrm{a}$ and $1.43 \mathrm{~d} / 10 \mathrm{a}$, respectively. The delay rate of the first frost day under RCP4.5 decreased significantly over time, while the decrease of the delay rate was insignificant under RCP8.5. While the slopes under RCP4.5 and RCP8.5 scenarios were lower compared to the baseline, the first frost day in Songnen Plain region still trended late from 1960 to 2099.

\subsubsection{Change in potential growing season in Northeast China}

Compared to the baseline scenario, growing seasons under RCP4.5 and RCP8.5 scenarios were lengthened by $4 \mathrm{~d}$ and $10 \mathrm{~d}$, respectively. As shown in Figures $7 \mathrm{a}, 7 \mathrm{~b}$ and $7 \mathrm{c}$, under both RCP4.5 and RCP8.5 scenarios, regions with all lengths of growing season expanded towards the north, with the expansion being greater in scale under RCP8.5. Under the RCP8.5 scenario for instance, regions with a growing season over $200 \mathrm{~d}$ nearly covered the entire Liaoning Province, while it only covered areas south of Liaoning Province under the baseline scenario. The region with a growing season of 180-200 d expanded north to southwest and east of Heilongjiang Province, while no such region existed in Heilongjiang Province under baseline. The region with a growing season of 140-200 d shrank significantly, and only existed in areas north of Inner Mongolia and northwest of Heilongjiang Province; it occupied the majority of northern Inner Mongolia and significant areas in northwest of Heilongjiang Province under the baseline scenario.

Furthermore, under future RCP4.5 and RCP8.5 scenarios, the growing season showed a 
lengthening trend throughout the entire region (Figure $7 \mathrm{~d}, 7 \mathrm{e}$ and $7 \mathrm{f}$ ). The average slopes under baseline, RCP4.5 and RCP 8.5 scenarios are $2.81 \mathrm{~d} / 10 \mathrm{a}, 1.30 \mathrm{~d} / 10 \mathrm{a}$ and $2.95 \mathrm{~d} / 10 \mathrm{a}$, respectively. The slope under the RCP8.5 scenario is larger than the baseline scenario. The slope under RCP4.5 is relatively small, yet it showed a lengthening trend over the entire Songnen Plain region.
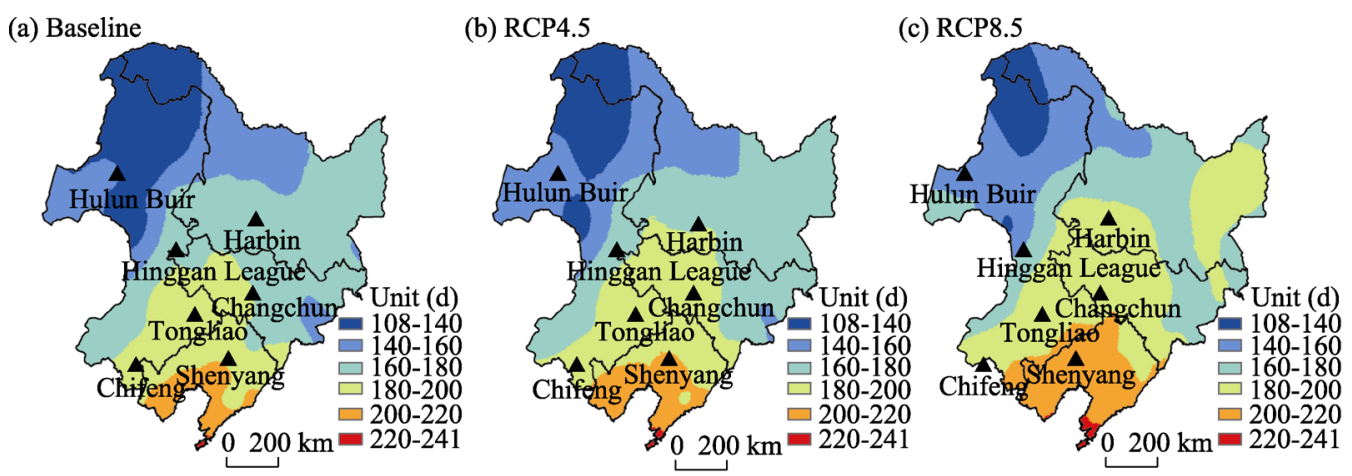

(d) Baseline

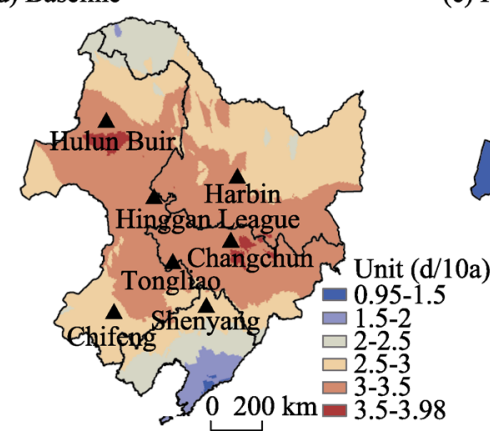

(e) RCP4.5

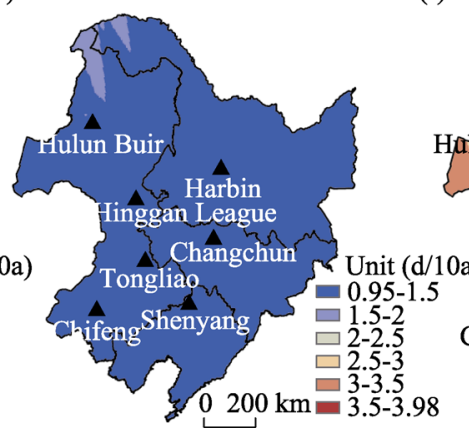

(f) RCP8.5

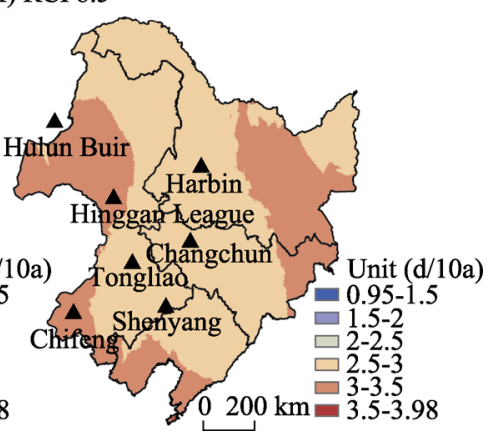

Figure 7 Spatial distribution of growing season length (a, b, c) and climate slope (d, e, f) with $80 \%$ assurance rate in Northeast China

\subsubsection{Changes in $\geqslant 10^{\circ} \mathrm{C}$ accumulated temperature in Northeast China}

Compared to the baseline scenario, the $\geqslant 10^{\circ} \mathrm{C}$ accumulated temperature increased significantly under RCP4.5 and RCP8.5 scenarios, with annual increments of $400^{\circ} \mathrm{C} \cdot \mathrm{d}$ and $700^{\circ} \mathrm{C} \cdot \mathrm{d}$, respectively (Figure 8 ). Under future RCP4.5 and RCP8.5 scenarios, regions with highly accumulated temperature levels expanded significantly towards the north. Low accumulated temperature level regions shrank significantly. The RCP8.5 scenario showed the highest increase in accumulated temperature. Under the baseline scenario, the region with accumulated temperature over $4000^{\circ} \mathrm{C} \cdot \mathrm{d}$ only occupied a small area in the south of Liaoning Province. Under the RCP4.5 scenario, it covered the majority of the areas in Liaoning Province. And under the RCP8.5 scenario, it covered Liaoning Province entirely and expanded to the west of Jilin Province and south of Inner Mongolia. Under the baseline scenario, accumulated temperature in most of Heilongjiang Province was $2000-2500^{\circ} \mathrm{C} \cdot \mathrm{d}$. Under future RCP4.5 and RCP8.5 scenarios, the accumulated temperatures over the region shifted to $3000-3500^{\circ} \mathrm{C} \cdot \mathrm{d}$ and $3500-4000^{\circ} \mathrm{C} \cdot \mathrm{d}$, respectively. The region with accumulated temperature 
less than $2000^{\circ} \mathrm{C} \cdot \mathrm{d}$ completely disappeared under the two future scenarios $\mathrm{RCP} 4.5$ and RCP8.5, and the area of the region with accumulated temperature at $2000-2500^{\circ} \mathrm{C} \cdot \mathrm{d}$ decreased significantly.

Under both of the future scenarios RCP4.5 and RCP8.5, the $\geqslant 10^{\circ} \mathrm{C}$ accumulated temperature exhibited an increasing trend in Northeast China. The slopes for baseline, RCP4.5 and $\mathrm{RCP} 8.5$ scenarios are $69^{\circ} \mathrm{C} \cdot \mathrm{d} / 10 \mathrm{a}, 41^{\circ} \mathrm{C} \cdot \mathrm{d} / 10 \mathrm{a}$ and $106^{\circ} \mathrm{C} \cdot \mathrm{d} / 10 \mathrm{a}$, respectively. The trend manifested as an increase in accumulated temperature over the entire region, and the increment was the highest under the RCP8.5 scenario.

(a) Baseline

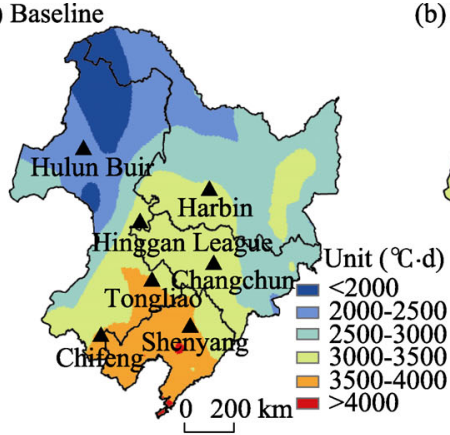

(b) RCP4.5

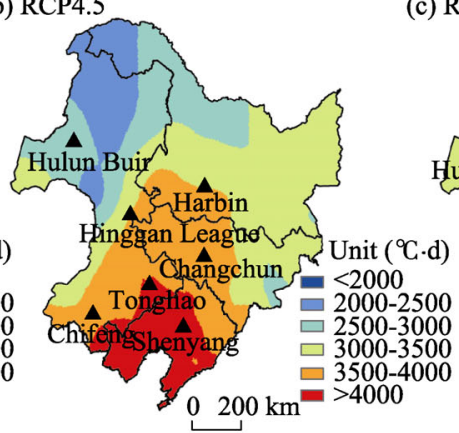

(c) RCP8.5

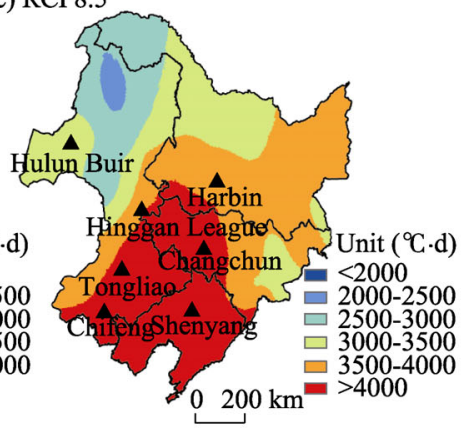

(d) Baseline

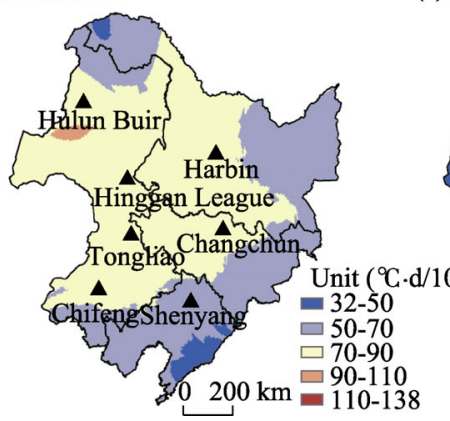

(e) RCP4.5

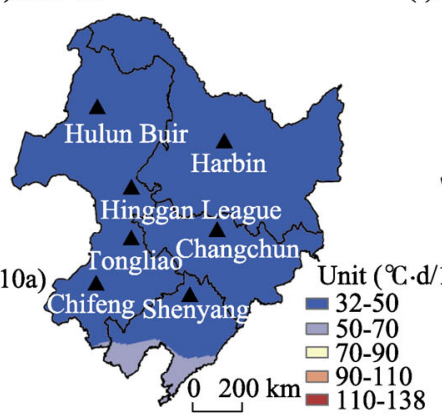

(f) RCP8.5

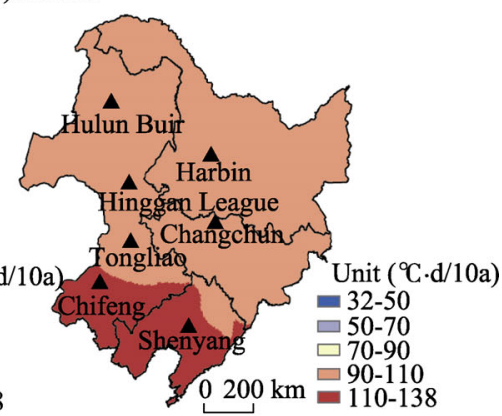

Figure 8 Spatial distribution of $\geqslant 10^{\circ} \mathrm{C}$ accumulated temperature $(a, b, c)$ and climate slope (d, e, f) with $80 \%$ assurance rate in Northeast China

\subsection{Future change in water resource in Northeast China}

Compared to the baseline scenario, precipitation under RCP4.5 and RCP8.5 scenarios showed a slight increase of $16 \mathrm{~mm}$ and $9 \mathrm{~mm}$, respectively (Figure 9). Under the three scenarios, the spatial distribution of precipitation was essentially the same, and exhibited a gradual decreasing trend from southeast to northwest, with local variations. For example, under RCP8.5, the region with 300-400 $\mathrm{mm}$ precipitation increased in area size but decreased in average precipitation in the southwest region. Precipitation in eastern Heilongjiang Province showed an increase, from the baseline scenario level of 400-500 $\mathrm{mm}$ to $500-600 \mathrm{~mm}$. Precipitation also increased at the southern boundary between Heilongjiang and Jilin provinces.

The slopes for average precipitation in growing season under RCP4.5 and RCP8.5 were $3.47 \mathrm{~mm} / 10 \mathrm{a}$ and $6.51 \mathrm{~mm} / 10 \mathrm{a}$, respectively. Both were higher than the $-5.93 \mathrm{~mm} / 10 \mathrm{a}$ under the baseline scenario, and showed an increasing trend. In the future Northeast China, pre- 
cipitation is projected to increase overall, but not at a significant level. The increment is faster in the eastern region, with the fastest increase occurring along the coastal areas, mainly around Liaodong Peninsula. Under the RCP4.5 scenario, Inner Mongolia and a part of Jilin Province showed a declining trend in precipitation. Under the RCP8.5 scenario, the only region with declining precipitation was around the Greater Khingan Mountains.

(a) Baseline

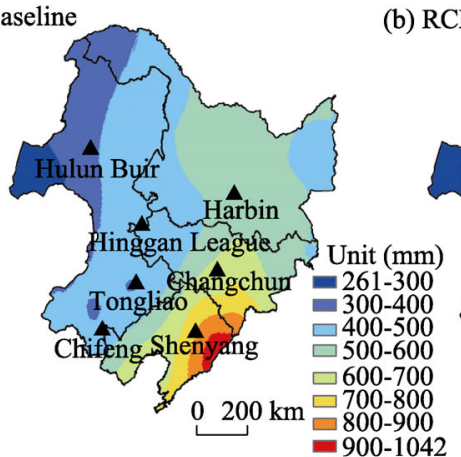

(b) RCP4.5

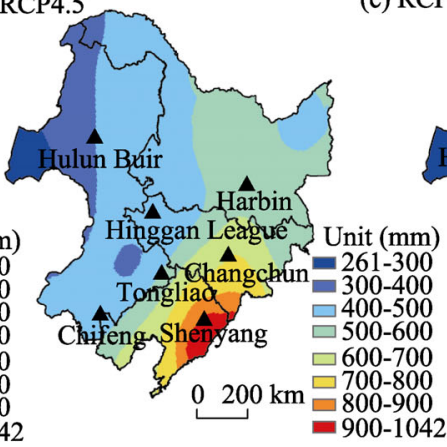

(c) RCP8.5

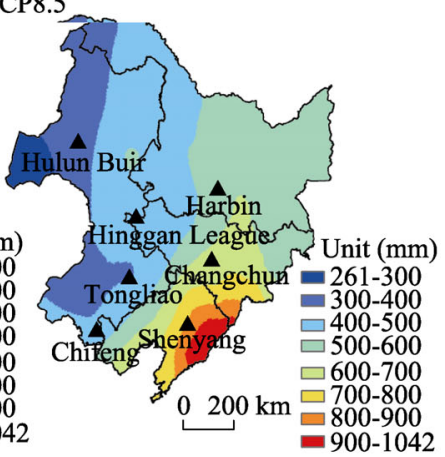

(d) Baseline

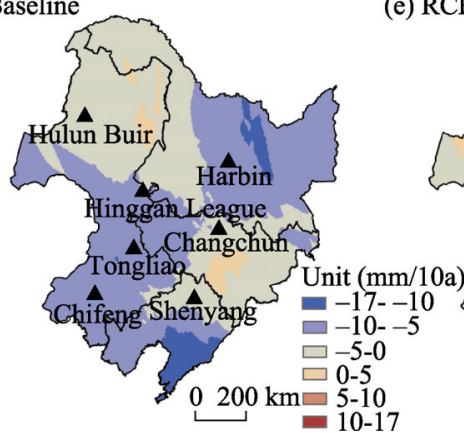

e) RCP4.5

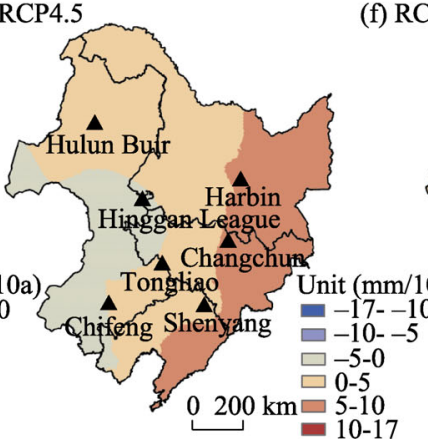

(f) RCP8.5

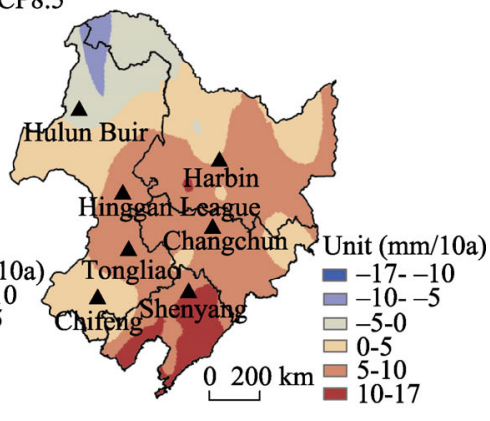

Figure 9 Spatial distribution of precipitation in growing season (a, b, c) and climate slope (d, e, f) with 80\% assurance rate in Northeast China

\section{Conclusions}

(1) From 1961 to 2099, influenced by climate change, the heat resource is projected to increase significantly, with a spatial distribution of higher in the south and lower in the north. The average temperature in Northeast China is trending higher, with temperature increments of $2^{\circ} \mathrm{C}$ and $3^{\circ} \mathrm{C}$ under low emission scenario RCP4.5 and high emission scenario RCP8.5, respectively. The first day with temperatures $\geqslant 10^{\circ} \mathrm{C}$ arrived $3-4 \mathrm{~d}$ earlier and the first frost day was delayed by $2-6 \mathrm{~d}$, leading to a $4-10 \mathrm{~d}$ increase in the potential growing season length. The temperature increase and lengthening of the growing season significantly increased the accumulated temperature. By the end of this century, the increment is projected to be 400 to $700^{\circ} \mathrm{C} \cdot \mathrm{d}$.

The significance tests for the slopes of heat resources in response to climate, temperature and accumulated temperature showed good results under the baseline scenario, with more than $80 \%$ of the data passing the significance test. The percentage of data that passed the significance test for the first frost day and potential growing season was $40 \%-50 \%$. The percentage for the first day with temperatures $\geqslant 10^{\circ} \mathrm{C}$ that passed the significance test was 
the lowest. Under future RCP4.5 and RCP8.5 scenarios, heat resources passed the test at a higher percentage, with a $100 \%$ pass rate for all heat resources under the RCP8.5 scenario.

The slope of heat resource variation changed significantly. The rate of temperature increase was faster under the high emission scenario. The slopes for RCP4.5 and RCP8.5 were $0.19 / 10 \mathrm{a}$ and $0.48 / 10 \mathrm{a}$, respectively, with even faster temperature increases in the north. The slopes for the first day with temperatures $\geqslant 10^{\circ} \mathrm{C}$ were $-0.54 \mathrm{~d} / 10 \mathrm{a}$ and $-1.51 \mathrm{~d} / 10 \mathrm{a}$, respectively, with the slope greater in the eastern and western regions. The slopes for the delay of first frost day were $0.75 \mathrm{~d} / 10 \mathrm{a}$ and $1.43 \mathrm{~d} / 10 \mathrm{a}$, respectively, with the delay being more prominent in the west and north. The slopes for potential growing season length were 1.30 $\mathrm{d} / 10 \mathrm{a}$ and $2.95 \mathrm{~d} / 10 \mathrm{a}$, respectively.

(2) From 1961 to 2099, under different future scenarios, the rate of change for agroclimatic resources showed variations. Compared to baseline, the increase in heat resources was faster and more prominent under the RCP8.5 scenario with unlimited emission. In comparison, the increase was slower under the RCP4.5 scenario.

(3) Water resource showed an increasing trend, but not at a significant level. From the yearly projections, precipitation will fluctuate significantly, with increasing frequency of extreme precipitation events. The range of fluctuation changed from $450-800 \mathrm{~mm}$ to 400-950 $\mathrm{mm}$. While the average precipitation is projected to increase in the future, the increase is insignificant. RCP4.5 scenario showed the highest increase in precipitation at 16 $\mathrm{mm}$, and the increment is less than 3\%. In summary, Northeast China is projected to change towards warmer and more humid conditions in the future, with significant increases in heat resources.

\section{Discussion}

(1) The impact of future climate change on agroclimatic resources will have a direct impact on agricultural production. Therefore, accurate analysis of the change in agroclimatic resources will be of significant importance to guiding agricultural production. Employing scenario-based climate data to analyze the impact of future climate change on agriculture has become a commonly used method to investigate the impact of future climate change on agriculture. As a result, scenario-based climate data are of crucial importance. Previously, IPCC's future scenarios were constructed based on greenhouse gases, suspended particulate matter, etc., with the same emission rate in all climate models. This yielded some limitations (Han et al., 2014). The latest RCPs proposed in the IPCC AR5 improved upon the scenario structure. The RCPs are based on atmospheric radiation, and take different emission policies into account to define criteria for temperature change. The process is more scientific and logical. This study was based on climate data under RCP scenarios, which makes the results more reliable.

(2) We used the AR5 scenarios to analyze the impact of climate change on agroclimatic resources in Northeast China. The results are in agreement with previous studies. By 2050, the average annual accumulated temperature increment is $205^{\circ} \mathrm{C} \cdot \mathrm{d}$, which matched well with conclusions reported by $\mathrm{Hu}$ Yanan and Liu Yingjie (2013) that showed an accumulated temperature increment of around $200^{\circ} \mathrm{C} \cdot \mathrm{d}$ in Northeast China using analysis based on RCP4.5. From 2071 to 2099 , under the $\mathrm{RCP} 4.5$ scenario, the $\geqslant 10^{\circ} \mathrm{C}$ accumulated temperature in 
Liaoning Province fluctuates between 3900 and $4500^{\circ} \mathrm{C} \cdot \mathrm{d}$, with a mean of $4200^{\circ} \mathrm{C} \cdot \mathrm{d}$. Under the RCP8.5 scenario, the $\geqslant 10^{\circ} \mathrm{C}$ accumulated temperature is $4300-5000^{\circ} \mathrm{C} \cdot \mathrm{d}$, with a mean of $4694^{\circ} \mathrm{C} \cdot \mathrm{d}$. Results of this study were comparable with findings reported by Yuan Bin et al. that the accumulated temperature of Liaoning Province will increase by $4000-5000^{\circ} \mathrm{C} \cdot \mathrm{d}$. From 2011 to 2050, the first frost day was delayed by $2 \mathrm{~d}$ under the RCP4.5 scenario and precipitation during the growing season fell by $12 \mathrm{~mm}$, which matched with results reported by Liu Jingli et al. (2012) using B2 scenario analysis.

(3) Climate change as represented by rising temperatures has certain positive impacts on agriculture in Northeast China. The expansion of the growing season and the increment of accumulated temperature deliver more usable heat resources to crops. Regions that were previously inarable because of limited heat resources will shrink. Arable regions will expand and crop breed variety will increase. Regions where early mature varieties are planted will now be able to grow mid-late mature varieties, and regions capable of growing late mature varieties will expand. For example, corn, a late mature variety, requires an accumulated temperature of $3000^{\circ} \mathrm{C} \cdot \mathrm{d}(\mathrm{Xu}, 2014)$, and its growing region can expand from the current Songnen Plain region to the north, up to areas around the Greater Khingan Mountains. In some parts of Liaoning Province, it may even be possible to plant varieties that can be harvested twice per year.

Yet, the negative impacts of climate change cannot be overlooked. Assuming that crop yield is not enhanced by technological developments and that the accumulated temperature requirement for each crop is unchanged within the growing season, the growing season will get shorter as the temperature accumulation gets faster with climate change. As a result, the dry mass accumulation period for crops will shrink, and thus lead to a reduction in overall yield. Liu Dan et al. (2013) found that the number of empty corn kernels increased when the temperature increased by $2^{\circ} \mathrm{C}$ under laboratory conditions, which led to a $40 \%$ reduction in yield. Additionally, water stress caused by the mismatch between temperature and precipitation will also potentially lead to reduced yield. Ma Shuqing et al. (2008) found that in regard to crop yield, the negative impact of water reduction outweighed the positive impact of temperature increases.

(4) In this study, we assimilated the output of climate model data with recorded historical data. Compared to traditional methods that only used modeling output data, data assimilation assured the rationality and consistency of the historical recorded data and the future modeling data. The resulting new time series thus closely approximates real climate conditions.

(5) The scenario data used in this study are the output of a regional climate model. The climate model takes various factors into consideration, in particular, using data assimilation to reduce systematic errors in the simulation. However, the variable nature of climate change adds inherent uncertainties to the future scenario data.

\section{References}

Alexandrov V A, Hoogenboom G, 2000. The impact of climate variability and change on crop yield in Bulgaria. Agricultural \& Forest Meteorology, 104(4): 315-327.

Dai Shuwei, Yang Xiaoguang, Zhao Meng et al., 2011. Changes of China agricultural climate resources under the background of climate change II: Spatiotemporal change characteristics of agricultural climate resources in Southwest China. Chinese Journal of Applied Ecology, 22(12): 3177-3188. (in Chinese) 
Füssel H M, Klein R J T, 2006. Climate change vulnerability assessments: An evolution of conceptual thinking. Climatic Change, 75(3): 301-329.

Gou Shiwei, Zhang Yingxian, Xu Yinlong, 2012. Analysis of climate resource changes during maize growth period in Ningxia under SRES A1B scenario. Chinese Journal of Eco-Agriculture, 20(10): 1394-1403. (in Chinese)

Han Leqiong, Han Zhe, Li Shuanglin, 2014. Projection of heavy rainfall events in the middle and lower reaches of the Yangtze River valley in the 21 st century under different representative concentration pathways. Transactions of Atmospheric Sciences, 37(5): 529-540. (in Chinese)

$\mathrm{Hu}$ Yanan, Liu Yingjie, 2013. Planting distribution of spring maize and its productivity under RCP4.5 scenario in Northeast China in 2011-2050. Scientia Agricultura Sinica, 46(15): 3105-3114. (in Chinese)

Li Qiang, 2012. The drought characteristics and its mechanism in the main arid regions of the globe in the background of global warming [D]. Lanzhou: Lanzhou University. (in Chinese)

Li Yong, Yang Xiaoguang, Dai Shuwei et al., 2010a. Spatiotemporal change characteristics of agricultural climate resources in middle and lower reaches of Yangtze River. The Journal of Applied Ecology, 21(11): 2912-2921. (in Chinese)

Li Yong, Yang Xiaoguang, Wang Wenfeng et al., 2010b. Change of China agricultural climate resources under the background of climate change I: Spatiotemporal change characteristics of agricultural climate resources in South China. The Journal of Applied Ecology, 21(10): 2605-2614. (in Chinese)

Lin Xiaosong, 2003. Research progress in the agroclimatic resources. Journal of Hainan Normal University, 16(4): 87-91. (in Chinese)

Liu Dan, Zhang Jiahua, Meng Fanchao et al., 2013. Effects of different soil moisture and air temperature regimes on the growth characteristics and grain yield of maize in Northeast China. Chinese Journal of Ecology, 32(11): 2904-2910. (in Chinese)

Liu Jingli, Ji Yanghui, Mi Na et al., 2012. Evolvement character of agricultural climate resources in Liaoning province from 2011 to 2050 based on B2 climate change scenarios. Journal of Meteorology \& Environment, 28(6): 81-87. (in Chinese)

Liu Zhijuan, Yang Xiaoguang, Wang Wenfeng et al., 2009. Characteristics of agricultural climate resources in three provinces of Northeast China under global climate change. The Journal of Applied Ecology, 20(9): 2199-2206. (in Chinese)

Ma Shuqing, Wang Qi, Luo Xinlan, 2008. Effect of climate change on maize growth and yield based on stage sowing. Acta Ecologica Sinica, 28(5): 2131-2139. (in Chinese)

Ma Yuping, Sun Linli, E Youhao et al., 2015. Predicting the impact of climate change in the next 40 years on the yield of maize in China. The Journal of Applied Ecology, 26(1): 224-232. (in Chinese)

Solomon S, 2007. Working Group 1 Contribution to the IPCC Fifth Assessment Report: Climate Change 2013: The Physical Science Basis.

Tang Guoping, Li Xiubin, Fischer G et al., 2000. Climate change and its impacts on China's agriculture. Acta Geographica Sinica, 55(2): 129-138. (in Chinese)

Wu Haiyan, Sun Tiantian, Fan Zuowei et al., 2014. The major food crops in response to climate change and its yield effect in Northeast of China. Journal of Agricultural Resources \& Environment, (4): 299-307. (in Chinese)

$\mathrm{Xu}$ Yanhong, 2014. Evaluation on the effect of adaptation countermeasures of maize on climate resources utilization in Northeast China under climate change [D]. Beijing: Chinese Academy of Meteorological Sciences. (in Chinese)

Yang Xiaoguang, Li Yong, Dai Shuwei et al., 2011. Changes of China agricultural climate resources under the background of climate change IV: Spatiotemporal change characteristics of agricultural climate resources in sub-humid warm-temperate irrigated wheat-maize agricultural area of Huang-Huai-Hai Plain. Chinese Journal of Applied Ecology, 22(12): 3177-3188. (in Chinese)

Yang Xuan, Tang Xu, Chen Baode et al., 2010. Impacts of climate change on wheat yield in China simulated by CMIP5 multi-model ensemble projections. The Journal of Applied Ecology, 21(10): 2605-2614. (in Chinese)

Yu Huning, 1985. Analysis and Use of Agricultural Climate Resources. Beijing: China Meteorological Press. (in Chinese)

Yuan Bin, 2012. Climatic potential productivity and climate resources utilization rate of spring maize in Northeast China under climate change [D]. Beijing: Chinese Academy of Meteorological Sciences. 